\title{
Comparison among the Role of Different Imaging Techniques in Diagnosis of Malignant Lesions Causing Obstructive Jaundice
}

\author{
F SALAM $^{\mathrm{a}}$, NF ISLAM ${ }^{\mathrm{b}}$, NAZMUL HUDA M. ${ }^{\mathrm{c}}, \mathrm{F}^{\text {PARVEEN }}{ }^{\mathrm{d}}$, T AFRIN $^{\mathrm{e}}, \mathrm{N} \mathrm{HAKIM} \mathrm{H.A}^{\mathrm{f}}$, TK SAHA $^{\mathrm{g}}$
}

\begin{abstract}
:
Introduction: The expanding spectrum of therapeutic options for patients with Obstructive /surgical jaundice makes it necessary for the surgeon to precisely assess the etiology, location, level and extent of disease before operation. Aims were to compare the diagnostic accuracy, sensitivity and specificity of different imaging techniques like ultrasonography (USG), Computed tomography (CT) and Magnetic Resonance Cholangiopancreatography (MRCP) and Endoscopic Retrograde Cholangiopancreatography (ERCP) in evaluation of patients with malignant obstructive jaundice and correlation of histopathological findings after surgical/ therapeutic intervention. Methods: It was a prospective observational study conducted in the Department of General Surgery and Hepatobilliary unit, Dhaka Medical College Hospital and Bangabandhu Sheikh Mujib Medical University, Dhaka during January 2015 to December 2015 for duration of one year to find out the role of different imaging techniques in diagnosis of malignant lesions causing obstructive jaundice in 50 cases who fulfilled the inclusion criteria. Initial USG evaluation was followed by CT scan, MRCP and ERCP. The results were read by radiologists blinded to other imaging findings. Surgically fit patients with a stage of resectability should be offered the option of surgical resection for cure. For unresectable malignancies, the choice is between surgical palliation/bypass and ERCP with drainage. The characteristic surgical
\end{abstract}

Introduction:

Jaundice is a common problem in medical and surgical gastroenterological practice. ${ }^{1}$ Obstructive jaundice is caused by the interruption of bile drainage in the biliary findings or ERCP features and histopathological diagnosis were recorded methodically as final. Results: Malignant obstructive jaundice is the commonest amongst the males and mean age was $47.56 \pm 13.191$ and the commonest etiology was Ca head of pancreas (30\%). Diagnostic accuracy of MRCP (98\%) in the diagnosis of malignant obstructive jaundice was relatively high (98\%) as compared to ERCP (89.5\%), CT (91.43\%), USG (89.97\%) in malignant obstructive jaundice respectively. In the diagnosis of malignant diseases, MRCP was more sensitive (95.83\%) as compared to ERCP (89\%), CT scan (91.67\%) and ultrasonography (78.17\%). Regarding specificity MRCP (100\%) was the high in comparison among ERCP (94\%), CT (90.91\%) and USG (96.15\%). Conclusion: It is concluded that malignant obstructive jaundice is the commonest amongst the males. Ca head of pancreas was the commonest malignant etiology in malignant obstructive jaundice. MRCP was superior to among USG, CT scan or ERCP in studying the malignant lesions.

Keywords: Imaging Techniques, Ultrasonography (USG), Computed tomography (CT) and Magnetic Resonance Cholangiopancreatography (MRCP) and Endoscopic Retrograde Cholangiopancreatography (ERCP),Malignant Lesions, Obstructive jaundice.

(J Bangladesh Coll Phys Surg 2021; 39: 233-240) DOI: https://doi.org/10.3329/jbcps.v39i4.55944

system. It is the most common type and is a serious hepatobiliary disease. It can cause problems in diagnosis and treatment, especially intrahepatic cholestasis. ${ }^{2}$ Malignant obstructive jaundice as this is more relevant

a. Dr. Farhana Salam, Junior Consultant, Department of Surgery, Kurmitola General Hospital, Dhaka-1206, Bangladesh.

b. Dr. Nadia Farzana Islam, Assistant Professor, Department of Surgery, Kurmitola General Hospital, Dhaka-1206, Bangladesh.

c. Dr. Nazmul Huda M., Medical Officer, Department of Urology, Dhaka Medical College Hospital, Dhaka-1000,Bangladesh

d. Dr. Farzana Parveen, Medical Officer, Department of Surgery, Kurmitola General Hospital, Dhaka-1206, Bangladesh.

e. Dr. Tangina Afrin, Assistant Registrar, Department of Burn \& Plastic, Sir Salimullah Medical College, Dhaka-1100, Bangladesh.

f. Dr. Nazmul Hakim H.A, Associate Professor, Department of Surgery, Dhaka Medical College, Dhaka-1000, Bangladesh.

g. Prof. Tapan Kumar Saha, Professor (Rtd), Department of Surgery, , Dhaka Medical College, Dhaka-1000,Bangladesh.

Address of Correspondence: Dr. Farhana Salam, E-mail: drfarhanasalam12@gmail.com, Cell+8801711100938

Receive: 26 November, 2020

Accept: 25 May, 2021 
to surgeons. Malignant obstructive jaundice is result of mechanical obstruction of bile ducts from primary pancreato-billiary malignancies or metastatic deposits from the lung, breast or melanoma. The most common cause of malignant billiary obstruction is pancreatic adenocarcinoma, followed by cholangiocarcinoma, ampullary neoplasm and extrinsic compression by a metastatic lymphadenopathy in the liver ${ }^{3}$.

Despite the technical advances, the operative modes of management of obstructive jaundice were associated with very high morbidity and mortality. Yet, during the last decade significant advances in have been made for the pathogenesis diagnosis, staging and the efficacy of management of obstructive jaundice ${ }^{4}$. The expanding spectrum of therapeutic options for the jaundiced patient has made it necessary for the surgeons to do more than simply discriminating between obstructive jaundice. Correct choices among therapeutic options usually rest upon a precise assessment of etiology, location, level and extent of disease ${ }^{5}$. So, it is mandatory to determine pre-operatively the existence, the nature and site of obstruction because an ill chosen therapeutic approach can be dangerous. Ultrasonography (USG) has been always considered the first choice technique in the study of biliary obstructive disease, due to its accessibility, speed, ease of performance and low cost ${ }^{6}$. Traditional Computed Tomography (CT) scan is usually considered more accurate than USG for helping determine the specific cause and level of obstruction ${ }^{7}$. Both USG and CT scan are regarded as safe and non-invasive procedures in evaluating the status of the biliary tract. USG is used as an initial modality to confirm or exclude duct obstruction, which it does with at least $90 \%$ accuracy ${ }^{8}$. The range of application of CT has been partially restricted by MRCP ${ }^{9}$. MRCP techniques have greatly evolved, providing high Radiology Section resolution images of the biliary tree with short exam duration, while remaining noninvasive without contrast medium injection ${ }^{10}$. The diagnostic accuracy, sensitivity and specificity of USG $93.13 \%$, $61.12 \%, 98.23 \%$ and $92.59 \%, 90.9 \%, 93.75 \%$ of CT and $93.13 \%, 90 \%, 94 \%$ of MRCP respectively ${ }^{11}$. ERCP also plays an important role in the diagnosis and palliation of pancreaticobiliary tumors. ${ }^{4}$ Radiographic findings may be suggestive of malignancy, but a definitive diagnosis requires tissue sampling. The overall results for determining the correct diagnosis was $89 \%$. The rationale for the use of ERCP lies in the possibility of taking histological samples and performing minimally invasive surgical interventions. The overall sensitivity of ERCP in combining the results of brush cytology, fine needle aspiration, and/or forceps biopsy in diagnosing pancreatic and biliary cancers ${ }^{11-13}$.

The aim of our study was to compare the diagnostic accuracy, sensitivity and specificity of different imaging techniques like ultrasonography (USG), Computed tomography (CT) and Magnetic Resonance Cholangiopancreatography (MRCP) and Endoscopic Retrograde Cholangiopancreatography (ERCP) in evaluation of patients with malignant obstructive jaundice and correlation of histopathological findings after surgical/ therapeutic intervention.

\section{Methods:}

It was a prospective observational study conducted in the Department of General Surgery and Hepatobilliary unit Dhaka Medical College Hospital and Bangabandhu Sheikh Mujib Medical University, Dhaka during January 2015 to December 2015 for duration of one year to find out the role of different imaging techniques in diagnosis of malignant lesions causing obstructive jaundice in 50 cases. Initial noninvasive like USG evaluation was followed by CT scan, MRCP and ERCP. The noninvasive tests like USG, CT and MRCP results were read by radiologists blinded to other imaging findings. The invasive ERCP are the gold standard technique for unresectable malignancies both in diagnostic and therapeutic procedures and were done by surgeons. Surgical palliation/bypass with drainage as well as biopsy is done by ERCP. Surgically fit patients with a resectable stage of tumor after imaging should be offered the option of surgical resection and histopathological diagnosis were recorded methodically as final. The statistical terms will be included in this study are mean, standard deviation, percentage. All statistical analysis were performed using SPSS 24.0 for Windows (SPSS Inc., Chicago, Illinois, USA) level of significance was set at .05 and $p$-value $<0.05$ was considered significant.

\section{Results:}

A prospective observational study was conducted in the Department of General Surgery and Hepatobilliary 
unit, Dhaka Medical College Hospital and Bangabandhu Sheikh Mujib Medical University, Dhaka. 50 patients with malignant obstructive jaundice (29 male and 21 female) and male: female ratio 1.38:1 were included in the study (Table1).

\section{Table-I}

\begin{tabular}{lccc}
\multicolumn{5}{c}{ Distributions of sex } \\
Sex & Frequency & Percent (\%) & Ratio \\
\hline Male & 29 & 58 & 1.38 \\
Female & 21 & 42 & 1 \\
\hline Total & 50 & 100.0 & \\
\hline
\end{tabular}

The mean ages of the patient group was within the range of $47.28 \pm 13.191$ and maximally were seen between in 30-70 years of age (Table II).

Table-II

\begin{tabular}{lcc}
\multicolumn{3}{c}{ Distributions of age } \\
Age in years & No of cases & Percent $(\%)$ \\
\hline$\leq 30$ & 4 & 8.0 \\
$30-50$ & 24 & 48.0 \\
$50-70$ & 19 & 38.0 \\
$>70$ & 3 & 6.0 \\
Total & 50 & 100.0 \\
Mean \pm SD & $47.56 \pm 13.191$ & \\
\hline
\end{tabular}

Each patient had multiple personal habits. Male had the highest incidence of smoking (52\%) and alcohol consumption (38\%) (Table III)

Table-III

\begin{tabular}{|c|c|c|c|c|}
\hline \multicolumn{5}{|c|}{$\begin{array}{l}\text { Habitual relationships in malignant } \\
\text { obstructive jaundice }\end{array}$} \\
\hline Personal history & Total & Percentage & Male & Female \\
\hline Smoking & 38 & 76 & $26(52 \%)$ & $12(24 \%)$ \\
\hline Betel nut & 15 & 30 & $7(20 \%)$ & $8(8 \%)$ \\
\hline Alcohol & 20 & 40 & $19(38 \%)$ & $1(2 \%)$ \\
\hline Total & 50 & 100 & $29(58 \%)$ & $21(42 \%)$ \\
\hline
\end{tabular}

Each patient had multiple symptoms and signs. Anorexia / weight loss (96\%), Clay coloured stools (92\%) and jaundice $(92 \%)$ were the most frequent clinical presentations (Table IV).
Table-IV

\begin{tabular}{lcc}
\multicolumn{3}{c}{$\begin{array}{c}\text { Symptoms and signs for malignant } \\
\text { obstructive jaundice }\end{array}$} \\
Symptoms and signs & Frequency* & Percent (\%) \\
\hline Anorexia/ weight loss & 48 & 96 \\
Clay coloured stools & 46 & 92 \\
Abdominal pain & 30 & 60 \\
Jaundice & 46 & 92 \\
Pruritis & 43 & 86 \\
Abdominal mass & 34 & 64 \\
Scratch marks & 27 & 54 \\
\hline Total & 266 & \\
\hline
\end{tabular}

*Each patient had multiple symptoms and signs

Ca head of pancreas(24\%) and Cholangiocarcinoma (20\%) were more common in male whereas Periampullary carcinoma(16\%) and Ca gall bladder(12\%) were more common in case female of all presented cases ( Table:5).

The diagnostic accuracy, for different malignant lesions confirmed by histopathology were as shown in Table: 6. Thirteen (13) out of 15 cases of Ca head of pancreas and DA is $86.67 \%, 13$ out of 14 cases of Cholangiocarcinoma and DA is $92.86 \%, 12$ out of 13 cases of periampullary carcinoma and DA is $92.30 \%$ and 7 out of 8 cases of Ca gall bladder and DA is $87.50 \%$ in which ultrasound were performed were accurately diagnosed. Ultrasound was unable to diagnose a specific cause for 3 cases where ERCP confirmed the diagnosis to be 2 cases cholangiocarcinoma and another periampullary carcinoma.

Fourteen(14) out of 15 cases of $\mathrm{Ca}$ head of pancreas and DA is $86.67 \%, 13$ out of 14 cases of Cholangiocarcinoma, 12 out of 13 cases of Periampullary carcinoma and 7 out of 8 cases of $\mathrm{Ca}$ gall bladder in which CT scan were performed and accurately diagnosed. CT scan was unable to diagnose a specific cause for 4 cases where final diagnosis confirmed the diagnosis to be periampullary carcinoma and rest 2 cases diagnosed as $\mathrm{Ca}$ head of pancreas

All cases of periampullary carcinoma and cholangiocarcinoma in which MRCP was performed were accurately diagnosed and there DA is $100 \%$. Fourteen(14) out of 15 cases of $\mathrm{Ca}$ head of pancreas 
and DA is $93.33 \%, 7$ out of 8 cases of $\mathrm{Ca}$ gall bladder and DA is $87.50 \%$ in which MRCP were performed and diagnosed.

Seven (7) cases of cholangiocarcinoma in which ERCP was performed were accurately diagnosed and the DA is $100 \%$. 5 out of 6 cases of Periampullary carcinoma and there DA is $83.33 \%$., 2 out of 4 cases of Ca head of pancreas and DA is 50\%. Cholangiocarcinoma, 3 out of 5 cases of Ca gall bladder and the DA is $100 \%$ in which ERCP were performed and accurately diagnosed.

The diagnostic accuracy, sensitivity and specificity of malignant lesions that causing malignant obstructive jaundice shown in Table: 7 . In case of Ca head of pancreas MRCP is more diagnostic (93.33\%) and ERCP is least (50\%). In case of Cholangiocarcinoma MRCP and ERCP are $100 \%$ diagnostic. In periampullary Ca MRCP is more diagnostic $100 \%$ but ERCP is least. For Ca gallbladder $\operatorname{MRCP}(87.66 \%)$ is more diagnostic than ERCP (60\%). Their sensitivity and specificity also reflect the result.

The overall accuracy, sensitivity and specificity of USG, CT, MRCP and ERCP in malignant lesions observed are as shown in Table: 8 . MRCP is the most reliable diagnostic technique where DA $98 \%$, SE $95.83 \%$ and SP $100 \%$.

Table-V

Distributions of Malignant Pathologies according to histopathology

\begin{tabular}{lcccc} 
Distributions of malignancy & Total & Percentage & Male & Female \\
\hline Ca head of pancreas & 15 & 30 & $12(24 \%)$ & $3(6 \%)$ \\
Cholangiocarcinoma & 14 & 28 & $10(20 \%)$ & $4(8 \%)$ \\
Periampullary carcinoma & 13 & 26 & $5(10 \%)$ & $8(16 \%)$ \\
Ca gall bladder & 8 & 16 & $2(4 \%)$ & $6(12 \%)$ \\
\hline Total & 50 & 100 & $29(58 \%)$ & $21(42 \%)$ \\
\hline
\end{tabular}

${ }^{*} \mathrm{Ca}=$ Carcinoma

Table-VI

\begin{tabular}{|c|c|c|c|c|c|c|c|c|c|c|c|c|}
\hline \multirow{2}{*}{$\begin{array}{l}\text { Malignancy } \\
\text { logical }\end{array}$} & \multicolumn{3}{|c|}{ USG } & \multicolumn{3}{|c|}{$\mathrm{CT}$} & \multicolumn{3}{|c|}{ MRCP } & \multicolumn{3}{|c|}{ ERCP } \\
\hline & $\begin{array}{c}\text { Histopatho- } \\
\text { logical } \\
\text { diagnosis }\end{array}$ & $\begin{array}{l}\text { Diagnosed } \\
\text { by USG }\end{array}$ & $\begin{array}{l}\mathrm{DA} \\
* \%\end{array}$ & $\begin{array}{c}\text { Histopatho- } \\
\text { logical } \\
\text { diagnosis }\end{array}$ & $\begin{array}{c}\text { Diagnosed } \\
\text { by CT }\end{array}$ & $\begin{array}{c}\mathrm{DA} \\
\%\end{array}$ & $\begin{array}{c}\text { Histopatho- } \\
\text { logical } \\
\text { diagnosis }\end{array}$ & $\begin{array}{c}\text { Diagnosed } \\
\text { by } \\
\text { MRCP }\end{array}$ & $\begin{array}{c}\mathrm{DA} \\
\%\end{array}$ & $\begin{array}{c}\text { Histopatho- } \\
\text { logical } \\
\text { diagnosis } \\
\end{array}$ & $\begin{array}{c}\text { Diagnosed } \\
\text { by } \\
\text { ERCP }\end{array}$ & $\begin{array}{l}\mathrm{DA} \\
* \%\end{array}$ \\
\hline $\begin{array}{l}\text { Ca head of } \\
\text { pancreas }\end{array}$ & 15 & 13 & 86.67 & 15 & 14 & 93.33 & 15 & 14 & 93.33 & 4 & 2 & 50 \\
\hline $\begin{array}{l}\text { Cholangio- } \\
\text { carcinoma }\end{array}$ & 14 & 13 & 92.86 & 14 & 13 & 92.86 & 14 & 14 & 100 & 7 & 7 & 100 \\
\hline Periampullary $\mathrm{Ca}$ & 13 & 12 & 92.30 & 13 & 12 & 92.30 & 13 & 13 & 100 & 6 & 5 & 83.33 \\
\hline Ca gall bladder & 8 & 7 & 87.50 & 8 & 7 & 87.50 & 8 & 7 & 87.50 & 5 & 3 & 60 \\
\hline
\end{tabular}

$\mathrm{DA}^{*}=$ diagnostic accuracy

Table-VII

\begin{tabular}{|c|c|c|c|c|c|c|c|c|c|c|c|c|}
\hline \multirow[t]{2}{*}{ Malignancy } & \multicolumn{3}{|c|}{ USG } & \multicolumn{3}{|c|}{$\mathrm{CT}$} & \multicolumn{3}{|c|}{ MRCP } & \multicolumn{3}{|c|}{ ERCP } \\
\hline & $\mathrm{DA} * \%$ & $\mathrm{SE}^{* * \%} \%$ & $\mathrm{SP} * * * \%$ & $\overline{\mathrm{DA} \%}$ & $\mathrm{SE} \%$ & $\mathrm{SP} \%$ & $\overline{\mathrm{DA} \%}$ & $\mathrm{SE} \%$ & $\mathrm{SP} \%$ & $\mathrm{DA} \%$ & $\mathrm{SE} \%$ & $\mathrm{SP} \%$ \\
\hline $\begin{array}{l}\text { Ca head of } \\
\text { pancreas }\end{array}$ & 86.67 & 72.3 & 94 & 93.4 & 89.33 & 97.90 & 93.33 & 89.40 & 98 & 50 & 68.3 & 88.5 \\
\hline $\begin{array}{l}\text { Cholangio- } \\
\text { carcinoma }\end{array}$ & 92.86 & 66.67 & 100 & 92.86 & 83.33 & 100 & 100 & 83.33 & 100 & 100 & 87.2 & 97 \\
\hline Periampullary $\mathrm{Ca}$ & 92.30 & 57.14 & 100 & 92.30 & 85.71 & 100 & 100 & 100 & 100 & 83.33 & 89 & 98 \\
\hline Ca gall bladder & 87.50 & 62.3 & 97 & 87.50 & 95.7 & 98.9 & 87.66 & 98.40 & 100 & 60 & 78.3 & 89.8 \\
\hline
\end{tabular}

$\mathrm{DA}^{*}=$ diagnostic accuracy, $\mathrm{SE}^{* *}=$ sensitivity, $\mathrm{SP} * * *=$ specificity 


\section{Table-VIII}

The Overall accuracy, sensitivity and specificity of USG, CT, MRCP and ERCP in malignant lesions

\begin{tabular}{|c|c|c|c|c|c|c|c|c|c|c|c|c|}
\hline \multirow[t]{2}{*}{ Malignant } & \multicolumn{3}{|c|}{ USG } & \multicolumn{3}{|c|}{ CT } & \multicolumn{3}{|c|}{ MRCP } & \multicolumn{3}{|c|}{ ERCP } \\
\hline & $\overline{\mathrm{DA}} \%$ & $\mathrm{SE} \%$ & $\mathrm{SP} \%$ & $\overline{\mathrm{DA}} \%$ & $\mathrm{SE} \%$ & $\mathrm{SP} \%$ & DA\% & $\mathrm{SE} \%$ & $\mathrm{SP} \%$ & DA\% & SE\% & $\mathrm{SP} \%$ \\
\hline $\begin{array}{l}\text { Malignant } \\
\text { conditions }\end{array}$ & 89.97 & 78.17 & 96.15 & 91.43 & 91.67 & 90.91 & 98 & 95.83 & 100 & 89.5 & 89 & 94 \\
\hline
\end{tabular}

$\mathrm{DA}=$ diagnostic accuracy. $\mathrm{SE}=$ sensitivity $\mathrm{SP}=$ specificity

\section{Discussion:}

The obstructive lesions of the biliary system are difficult problem for the surgeon as most of the patients are old and major surgical risks ${ }^{2}$. This prospective study was conducted in two tertiary referral centers in Dhaka where subjects who were referred from different areas of the country. This study was done in a defined population revealed clinically the causes of obvious malignant obstructive jaundice in our setting over a 1 year period, the jaundice being proved by history, examination and proper laboratory investigations. The patients were selected who fill the inclusion and exclusion criterias and had malignant obstructive jaundice.

In this study, malignant obstructive jaundice is found more in the males than females. The male to female ratio was 1.38:1 for the malignant obstructive jaundice and male had history of smoking (52\%) and alcohol abuse $(38 \%)$ more than female. The increased incidence of malignant obstructive jaundice amongst the males is due to smoking and possibly related to alcohol abuse 14-16 which is consistent with our observation.

The mean age of the patients with the malignant etiology of obstructive jaundice was $47.56 \pm 13.191$ years. It was more common in the older patients and was maximally seen between 30-70 years of age. One recent study showed that the increased incidence of malignant obstructive jaundice with the increasing age 17 .

Our observation showed that each patient had multiple symptoms and signs. Among the symptoms and signs anorexia/ weight loss (96\%), clay coloured stools (92\%) and jaundice $(92 \%)$ were the most frequent clinical presentation in the patients of malignant jaundice. Some literature presented that clay coloured stools and jaundice were reported more commonly by patients with the malignant jaundice. Pruritis and abdominal pain were also seen equally in malignant cases. While almost $30 \%$ of the patients with malignancy also had abdominal pain on presentation possibly due to advanced disease ${ }^{18}$, ${ }^{19}$. The abdominal masses was appreciated in $30 / 50(60 \%)$ of the patients with malignancy due to the local spread of tissues thus supporting the 'Courvoisier's law' ${ }^{20}$. The scratch marks were also seen in malignant conditions. The presence of these signs and symptoms has also been confirmed by other studies ${ }^{17-18,21-22}$.

Regarding the diagnosis, Ca head of pancreas (30\%) was the commonest amongst the malignancies, followed by Cholangiocarcinoma (28\%), Periampullary carcinoma $(26 \%)$ and Ca gall bladder (16\%) in our series. Similar incidence of various malignancies in patients of obstructive jaundice has been shown in various studies $16-17,22-23$. Six (12\%) female patients and two (4\%) male had Ca gall bladder also had gall stones. The association of Carcinoma Gall Bladder with gall stones has been reported in literature $15-16,21-22$. . The patients with these malignancies also had the palpable masses in the right hypochondrium thus supporting the Courvoisier's law. ${ }^{20}$

Amongst the diagnostic radiological investigations USG abdomen picked the dilated intra-hepatic channels in $24 \%$; the dilated extra-hepatic in $22 \%$ while CBD stones were found in $12 \%{ }^{23}, 24$. The CBD was found to be dilated in $24 \%$ of the patients and its measurement ranged from $1.4 \mathrm{~cm}$ to $2.4 \mathrm{~cm}$ with a mean value of $1.46 \mathrm{~cm}$. Mass was picked up in only $26 \%$ of the patients and most of the time it was mass of head of pancreas and diagnostic accuracy was $85 \%{ }^{25}$. The diagnostic accuracy of by USG was $\mathrm{Ca}$ head of pancreas $87.2 \%$, Cholangiocarcinoma, $92.86 \%$, Periampullary $\mathrm{Ca} 92.30 \%$, Ca gall bladder $87.50 \%$ and overall diagnostic accuracy $89.97 \%$. So this study was considered reliable in the other studies as well ${ }^{23,24}$.

The overall sensitivity was $66.67 \%$, specificity was $100 \%$ and accuracy was $92.86 \%$ for cases with cholangiocarcinoma on USG in our present research 
was consistent previously reported study that USG detected $87 \%$ of Klatskin's tumor 26 . One study demonstrated that the sensitivity and specificity of $88.4 \%$ and $85.3 \%$ on USG , $94.2 \%$ and $85 \%$ on CT, $86 \%$ and $92 \%$ respectively for detecting the malignant etiology of obstruction ${ }^{27}$.

This present study showed that sensitivity, specificity and diagnostic accuracy respectively $95.83 \%, 100 \%$ and $98 \%$.

Among literatures review showed that diagnostic accuracy, sensitivity and specificity of MRCP are comparable to those reported in those studies where sensitivity, specificity and diagnostic accuracy respectively range between $81-100 \%, 84-100 \%$ and 90 $96 \% 11,28,29$. Another study concluded in their study that MRCP was more accurate than $\mathrm{CT}$ in differentiating between malignant and benign lesions in patients with suspected periampullary tumors ${ }^{30}$. This is consistent with present study where MRCP showed $100 \%$ accuracy in diagnosing cases with periampullary carcinoma.

ERCP was performed in the most of the cases where needed therapeutic intervention as well as diagnostic procedure ${ }^{32}$. The results of ERCP in picking up the diagnosis in case of malignant obstructive jaundice was relatively good but it was not possible to perform ERCP in all cases as it was difficult to cannulate the Ampulla of Vater either because of localized oedema or because of the external compression caused by the tumour ${ }^{31}$. Though the findings in these cases included projections from the ampulla and dilated duodenum. ERCP revealed dilated CBD in about $74 \%$ of cases who had malignancy either because of $\mathrm{Ca}$ Head of Pancreas, Ca Gall Bladder and Cholangiocarcinoma. One of the study also showed that the diagnosis of these tumours can be diagnosed by ERCP ${ }^{32}$. CT-Scan was done for all the cases suspected of malignancy and the ones in which ERCP was unsuccessful and the diagnosis was made on the basis of its findings. ${ }^{12,33}$. Eighteen patients $(30 \%)$ had CaHead of Pancreas, 8 patients (13.33\%) had Ca Gall Bladder, $7(11.66 \%)$ had Cholangiocarcinoma with $2(3.33 \%)$ having the Klatskin's tumour, $1(1.66 \%)$ patient had the Periampullary carcinoma ${ }^{34}$. The present study showed that $7(14 \%)$ cases of cholangiocarcinoma in which ERCP was performed were accurately diagnosed. $5(10 \%)$ out of 6 cases of Periampullary carcinoma, 2(4\%) out of 4 cases of Ca head of pancreas Cholangiocarcinoma, $3(6 \%)$ out of 5 cases of $\mathrm{Ca}$ gall bladder in which ERCP were performed and accurately diagnosed.

The final diagnosis was then made based upon the results of histopathology and then results were drawn. Literature reviews of various others centers showed that the diagnostic accuracy of USG in defining the malignant obstruction was $91.8 \%$ as compared to 97.5 $\%, 90 \%$ and $100 \%$ for CT scan, MRCP and ERCP respectively. The studies showed that sensitivity for a diagnosis of malignant diseases was $88.4 \%, 94.2 \%$, $92.3 \%$ and $100 \%$ for USG, CT, MRCP and ERCP respectively whereas specificity was $85.3 \%, 85 \%, 98 \%$ and $100 \%$ respectively $11,18,31,19-22$. Above these studies were consistent with our present observation. However the relatively lower sensitivities noted in older studies with regard to USG and CT could be due to resolution and technical factors which have vastly improved in last decade and hence this study sheds new light on diagnostic accuracies of the modern high tech equipment (including high resolution USG and spiral CT) in context to biliary obstruction ${ }^{14,21}$. The final diagnosis was then made based upon the results of histopathology (post ERCP/biopsy/cytology/surgery) and then results were drawn and analyzed.

\section{Conclusion:}

The malignant obstructive jaundice was the commonest amongst the males. $\mathrm{Ca}$ head of pancreas was the commonest malignant etiology in malignant obstructive jaundice. MRCP was the modality of choice for optimal characterization of the causative lesions in most of the cases of obstructive jaundice. MRCP was superior to among USG and CT scan or ERCP in studying the malignant lesions.

\section{Limitations of the study:}

The study was conducted in only two centers in Dhaka city which might not be representative to the whole population. Small sample size was a limitation of the present study. Moreover the duration of follow up was also short.

Funding: No funding sources.

\section{Conflict of interests:}

The authors declare that there was no conflict of interests regarding the publication of this paper.

\section{Acknowledgement:}

We would like to show our gratitude to the faculty members of the Department of General Surgery and 
Hepatobilliary unit, Dhaka Medical College Hospital and Bangabandhu Sheikh Mujib Medical University, Dhaka for sharing their pearls of wisdom with us during the course of this research. We are also immensely grateful to doctors and staffs of these institutes for their unconditional supports for collecting data.

\section{References:}

1. Whitehead MW, Hains Worth I, Kingham JG. The causes of obvious jaundice in southwest Wales: perceptions vs reality. Gut 2001; 48:409-13. https://doi.org/10.1136/ gut.48.3.409 PMid:11171834 PMCid:PMC1760136

2. Nikolaidis P, Hammond NA, Day K, Yaghmai V, Mosbach DS, Harmath CB, Taffel MT, Horowitz JM, Berggruen M, Miller FH. Imaging features of benign and malignant ampullary and peri-ampullary lesions. Radiographics 2014;34(3):624-641. https://doi.org/10.1148/ rg.343125191 PMid:24819785

3. Briggs $\mathrm{M}$, Peterson $\mathrm{CD}$. Investigation and management of obstructive jaundice: Surgery. 2007; 25(20): 74-80. https:/ /doi.org/10.1016/j.mpsur.2007.01.005

4. Kahnag Kim U, Roslyn Joel J. Jaundice. Maingot's abdominal operations.10thedition. Vol.I \& II. Singapore: McGraw Hill; 2001. pp. 315-336.pp. 1701-2031.

5. Oikarinen H. Overview of current strategies for diagnostic imaging of biliary tract and gall bladder tumors. In: Herman JM, Pawlik TM, Thomas CR (eds) Biliary tract and gall bladder cancer: a multisciplinary approach, 2nd edn. Springer, 2014;pp 118-129. https://doi.org/10.1007/9783-642-40558-7_8 https://doi.org/10.1007/978-3-64240558-7_8

6. Hakansson K, Ekberg O, Hakansson HO, Leander P. MR and ultrasound in screening of patients with suspected biliary tract disease. Acta Radiol. 2002; 43:80-86. https://doi.org/ 10.1080/028418502127347493 PMid:11972468

7. Zhang ZY, Wang D, Ni JM, Yu XR, Zhang L, Wu WJ, Gong $\mathrm{L}, \mathrm{Hu} \mathrm{MH}$. Comparison of three-dimensional negative contrast CT cholangiopancreatography with threedimensional MR cholangiopancreatography for the diagnosis of obstructive biliary diseases. Eur J Radiol. 2012; 81(5):830837. https://doi.org/10.1016/j.ejrad.2011.02.036 https:// doi.org/10.1016/j.ejrad.2011.02.036 PMid:21377820

8. Lee DH, Kim B, Lee ES, Kim HJ, Min JH, Lee JM, Choi MH, Seo N, Choi SH, Kim SH, Lee SS, Park YS, Chung YE (2021) Radiologic evaluation and structured reporting form for extrahepatic bile duct cancer: 2019 consensus recommendations from the Korean Society of Abdominal Radiology. Korean J Radiol. 2021;22(1):41-62. https:// doi.org/10.3348/kjr.2019.0803 PMid:32901457 PMCid:PMC7772383
9. Zandrino F, Benzi L, Ferretti ML, et al. Multislice CT cholangiography without biliary contrast agent: technique and initial clinical re- sults in the assessment of patients with biliary obstruction. Eur Radiol. 2002; 12:1155-61. https://doi.org/10.1007/s00330-001-1188-y PMid: 11976862

10. Liu TH, Consorti ET, Kawashima A, Tamm EP, Kwong KL, Gill BS, et al. Patient evaluation and management with selective use of magnetic resonance cholangiography and endoscopic retrograde cholangiopancreatography before laparoscopic cholecystectomy. Ann Surg. 2001;234:3340. https://doi.org/10.1097/00000658-200107000-00006 PMid:11420481 PMCid:PMC1421945

11. Boraschi P, Neri E, Braccini G, et al. Choledocholithiasis: diagnostic accuracy of MR cholangiopancreatography. Three-year experience. Magn Reson Imaging. 1999; 17:1245-53. https://doi.org/10.1016/S0730-725X(99) 00075-2

12. Calvo MM, Bujanda L, Calderon A, et al. Role of magnetic resonance cholangiopancreatography in patients with suspected choledocholithiasis. Mayo Clin Proc. 2002; 77:422-28. https://doi.org/10.1016/S0025-6196(11) 62210-6

13. Mathew RP, Moorkath A, Basti RS, Suresh HB (2016) Value and accuracy of multidetector computed tomography in obstructive jaundice. Pol J Radiol. 2016; 81:303-309. https://doi.org/10.12659/pjr.896680 https://doi.org/10.12659/ PJR.896680 PMid:27429673 PMCid:PMC4928501

14. Channa NA, Khand FD, Bhanger MI, Leghari MH. Surgical incidence of Cholelithiasis in Hyderabad and adjoining areas (Pakistan). Pak J Med Sci 2004; 20:13-7.

15. Zarin M, Ahmed M, Gohar A, Wah eed D, Khurram S et al. Incidence of gall stones in carcinoma Gall Bladder patients. Pak J Surg 2005; 21:19-22.

16. Ullah N, Gondal SK, Shahbaz RA. Carcinoma Gall Bladder; an incidence study at Services Hospital Lahore. Pakistan Postgrad Med J 2000;11:156-7.

17. Aziz M, Ahmad N, Faizullah. Incidence of malignant obstructive jaundice-A study of hundred patients at Nishtar Hospital Multan. Ann KE Med Coll 2004;10:71-3 https:// doi.org/10.21649/akemu.v10i1.1159

18. Sharma MP, Ahuja V. Aetiological spectrum of obstructive jaundice and diagnostic ability of ultrasonography clinician's perspective. Trop Gastroenterol.1999; 20:67-9.

19. El-gerby KM, Elsamak A, Khalil OE, Shawky KM, ElKady H Role of magnetic resonance imaging and magnetic resonance cholangiopancreatography versus helical computed tomography in evaluation of biliary obstruction. MD thesis, Faculty of Medicine, Zagazig University. 2006. https://doi.org/10.21608/ZUMJ.2019.14168.1291 https:/ /doi.org/10.21608/zumj.2019.14168.1291 
20. Russell R.C.G. The Gall Bladder and bile duct. In: Russell R.C.G, Williams N.S, Bulstrode C.J.K. Bailey \& Love' short practice of Surgery. 24 th ed. London: Arnold publishers, 2004; p.1094-5, 1103-6.

21. Samad A. Gall bladder carcinom a in patients undergoing Cholecystectomy for cholelithi asis. J Pak Med Assoc 2005; $55: 497-9$.

22. Rahman A, Shah SMA, Khan N, Arif A, Asadullah. Frequency of carcinoma Gallbladder in patients undergoing surgery for chronic cholecystitis with cholelithiasis. J Med Sci 2006; $14: 26-9$.

23. Cheema KM, Ahmad F, Gondal SH. Evaluation of etiological incidence and diagnostic modalities in obstructive jaundice. Pak Postgrad Med J 2001; 12:160-4.

24. Ghaffar A, Buledi GQ, Imran M. Role of imaging in obstructive jaundice J Surg Pakistan 2004;9:24-6.

25. Heller MT, Borhani AA, Furlan A, Tublin ME. Biliary strictures and masses: an expanded differential diagnosis. Abdom Imaging. 2015; 40(6):1944-1960. https://doi.org/ 10.1007/s00261-014-0336-1 https://doi.org/10.1007/ s00261-014-0336-1 PMid:25542219

26. Hyodo T, Kumano S, Kushihata F, Okada M, Hirata M, Tsuda T, Takada Y, Murakami T (2012) CT and MR cholangiography: advantages and pitfalls in perioperative evaluation of biliary tree. Bi J Radiol. 2012; 85(1015):887-896. https:/ /doi.org/10.1259/bjr/21209407 https://doi.org/10.1259/bjr/ 21209407 PMid:22422383 PMCid:PMC3474084

27. Francesco SF, Federica Fantozzi, Laura Tasciotti, Francesco Vigni, Francesca Scotto, Paolo Frasci. A comparative study in 131 patients with suspected biliary obstruction. Med Sci Monit. 2005; 11(3):8-18.

28. Hussein FM, Alsumait B, Aman S, et al. Diagnosis of choledocholithiasis and bile duct stenosis by magnetic resonance cholangiogram. Australas Radiol. 2002;46:4146. https://doi.org/10.1046/j.1440-1673.2001.00992.x PMid:11966585

29. Varghese Liddell, et al. MRCP versus U/S in the detection of choledocholithiasis. Clinical radiology. 2000; 55:25-35. https://doi.org/10.1053/crad.1999.0319 PMid:10650107

30. Andersson M, Kostic S, Johansson M, Lundell L, Asztély M, Hellström M. MRI combined with MR cholangiopancreatography versus helical CT in the evaluation of patients with suspected periampullary tumors: a prospective comparative study. Acta Radiol. 2005 Feb; 46(1):16-27. https://doi.org/10.1080/02841850510016018 PMid: 15841735

31. Acalovschi M. Cholangiocarcinoma: risk factors, diagnosis and management. Rom J Intern Med 2004; 42:41-58.

32. deBellis M, Sherman S, Fogel EL. Tissue sampling at ERCP in suspected malignant biliary strictures (Part 1). Gastrointest Endosc 2002; 56:552-61. https://doi.org/ $10.1016 / \mathrm{S} 0016-5107(02) 70442-2$

33. Awan MW, Nasir N, Yasrab, Ather S (2016) Accuracy of MDCT cholangiography using image reformation in cases of biliary tract obstruction comparing with ERCP. ISRA Med J. 2016; 8(4):220-223

34. Oldhafer K, J, von Hahn T: Klatskin Tumors: Challenging as Ever. Visc Med 2021; 37:1-2. doi: 10.1159/000514019 https://doi.org/10.1159/000514019 PMid:33718478. 